\title{
Arthroplasty versus internal fixation for intertrochanteric fractures in the elderly: A meta-analysis
}

\author{
Kexiao Yu \\ chongqing traditional chinese medicine hospital \\ Weizhong Lu \\ chongqing traditional chinese medicine hospital \\ Qiuke Xiao \\ chongqing traditional chinese medicine hospital \\ Ruijie Wan \\ chongqing traditional chinese medicine hospital \\ Lujue Dong \\ chongqing traditional chinese medicine hospital \\ Zhenyu Dai ( $\nabla$ zhenyudai@cdutcm.edu.cn) \\ chongqing traditional chinese medicine hospital
}

\section{Research article}

Keywords: Internal fixation; Arthroplasty; intertrochanteric fracture; Meta-analysis

Posted Date: April 30th, 2020

DOI: https://doi.org/10.21203/rs.3.rs-22149/v1

License: (c) (i) This work is licensed under a Creative Commons Attribution 4.0 International License. Read Full License 


\section{Abstract \\ Background}

Surgical treatment is the first choice for intertrochanteric fractures in the elderly as it allows early rehabilitation and functional recovery. Recently, more and more surgeons prefer arthroplasty instead of internal fixation in the treatment of senile intertrochanteric fractures. However, there is conflicting evidence as to which is the best surgical treatment for them. In this article, we performed a systematic review and meta-analysis to compare the clinical effectiveness of internal fixation (IF) and arthroplasty (AR) for intertrochanteric fractures in the elderly.

\section{Methods}

The online databases of PubMed, Cochrane Database, and Web of Science were searched to include studies conducted from 01/01/2000 to $11 / 30 / 2018$ in English using keywords to identify articles relevant to this study. All studies had to have evaluated the treatment of patients with intertrochanteric fractures in the elderly ( $\geq 60$ years of age). The quality of the trials was assessed and meta-analyses were conducted using the Cochrane Collaboration's RevMan 5.3 version.

\section{Results}

A total of 14 studies involving a total of 1588 patients were suitable for inclusion in this meta-analysis. There was no significant difference between the IF and AR groups for postoperative complications-related general condition $(\mathrm{OR}=1.24 ; 95 \% \mathrm{Cl}=0.90,1.70 ; P=0.19)$, hospital stay $(\mathrm{SMD}=0.16$; $95 \% \mathrm{Cl}=-0.5,0.82 ; P=0.64)$, and Harris hip score $(\mathrm{SMD}=-0.12 ; 95 \% \mathrm{Cl}=-0.79,0.54 ; P=0.71)$. AR group had a significantly lower rate of complications-related operation $(\mathrm{OR}=2.21 ; 95 \% \mathrm{Cl}=1.41,3.45 ; P=0.0005)$ and reoperation $(\mathrm{OR}=2.74 ; 95 \% \mathrm{Cl}=1.57,4.76 ; P=0.0004)$. However, compared with AR group, IF group could reduce the blood loss $(\mathrm{OR}=-4.08 ; 95 \% \mathrm{Cl}=-4.58,-3.59 ; P<0.00001)$, transfusion requirement $(\mathrm{SMD}=-0.67$; $95 \% \mathrm{Cl}=-1.08,-0.26 ; P=0.001)$, operation time $(\mathrm{SMD}=-0.80 ; 95 \% \mathrm{Cl}=-1.47,-0.12 ; P<0.00001)$, and have a lower rate of mortality within $1-\mathrm{year}(\mathrm{OR}=$ $0.67 ; 95 \% \mathrm{Cl}=0.52,0.86 ; P=0.002)$.

\section{Conclusion}

AR is associated with less rates of complications-related operation and reoperation but has an increased risk of blood loss, transfusion, operation time and mortality within 1-year. Our findings demonstrated that AR does not have significant advantages over IF for intertrochanteric fractures in the elderly.

\section{Introduction}

Intertrochanteric fracture (ITF) is one of the common fractures in the elderly, and its incidence is also increasing with the rapid growth of the aging population. ${ }^{1,2}$ Recent epidemiologic studies reported that about 1.7 million new ITFs occur in the world every year, which account for $8-10 \%$ of all fractures, and the number is expected to double by the year 2040. ${ }^{3,4}$ It presents a major public health concern for current society. ${ }^{5}$ The ITFs in the elderly usually result from minor trauma, but they are very difficult to achieve and maintain a stable fixation because of their poor bone quality. ${ }^{6}$ The treatments for the ITF normally include surgical and non-surgical treatment. The non-surgical treatment has been not adopted basically with reported mortality rates ranging from $15-30 \%$, and complications such as pneumonia, urinary tract infection and cardiovascular events. 7,8 The surgical treatment has been demonstrated that it can decrease the mortality rates, complications and significantly improve the quality of life of the patients after surgery. ${ }^{9-12}$ Therefore, it has been considered as first choice for the elderly patients with ITFs.

The surgical options include the open or closed reduction internal fixation (OR/CRIF) and arthroplasty (AR). The IF has been the preferred treatment for the elderly patients with ITFs over the years, because it can enable the patient to have postoperative early mobilization, less complications, and good functional recovery. ${ }^{13-15}$ However, with the development of prosthesis design, the AR has gradually become another considerable treatment for the elderly patients with ITFs. ${ }^{16}$ There have been a few nonrandomized and randomized studies comparing IF and AR for the treatment of ITFs, but which is the best surgical treatment for the elderly patients with ITFs has been controversial in the past ten years. ${ }^{17-22}$ The nonrandomized clinical studies have been limited due to lack of the assessments of possible confounding variables, independent outcome, and possible bias associated with unmeasured or unknown confounders inherent in observational studies. ${ }^{23}$ Even if randomized controlled trials (RCTs) have decreased bias through randomization and overcome the limitations of nonrandomized studies. However, it is obvious that human subjects cannot ethically be randomized to exposure to a potentially noxious factor and alternative therapies for the same disease are so different that it is unlikely that patients would be indifferent to their choices to the degree that they consent to randomization. Sometimes, it is not possible to randomize exposure to a risk factor at all. ${ }^{24}$ Thus, the purpose of the current meta-analysis is to assess the evidence from the previous RCTs and non-RCTs that have compared the clinical efficacy of IF and AR for treating the elderly patients with ITFs. 


\section{Materials And Methods}

\section{Search Strategy}

The sources included PubMed, Cochrane Database, and Web of Science databases were searched from 01/01/2000 to 11/30/2018. The search terms included intertrochanteric, or pertrochanteric, or trochanteric; internal fixation; and arthroplasty, or hip replacement, or prosthetic replacement. All searches were limited to the English language. Information was carefully extracted from all the eligible studies by two investigators independently, using a standardized data extraction form. Any disagreement was resolved by discussion during a consensus meeting with other investigators.

\section{Inclusion Criteria and Data Extraction}

The selection criteria used to determine the eligible studies included: (1) the objects of study were elderly patients ( $\geq 60$ years age) with ITFs; (2) the literature was RCT or non-randomized comparative study; (3) the treatment was internal fixation versus arthroplasty; (4) the comparative data must include at least one of the following results: available operative time, blood loss volume, transfusion, hospital stay, mortality, reoperation rate and major method/general-related complication data; (5) limited to patients with normal mental; (6) no serious known metastatic disease or terminal illness; (7) the follow-up period was at least 6 months.

We extracted data from relevant studies using an electronic data collection form prepared in Stata software. We contacted study authors, where appropriate, to request further information, such as missing results. The following information was extracted from the eligible studies: first author's name, year of publication, participants' age and gender, number of participants in each group, study design (cohort, case-control, cross-sectional), follow-up time, and the major outcomes.

\section{Statistical Analysis}

The statistical analysis was conducted using the Cochrane Collaboration's Rev Man 5.3 software (Nordic Cochrane Centre, Copenhagen, Denmark). The summary odds ratio (OR) was used as the effect parameter for this meta-analysis, and a 95\% confidence interval (Cl) was used to interpret the results. Heterogeneity was assessed using the $R^{2}$ value and Chi-square test. It was conducted to determine whether the results of various studies and the overall effects are consistent or not. If the outcome data was low heterogeneity $(P \geq 0.05, P \leq 50 \%)$, a fixed-effect model would be used for analysis. If there was statistical heterogeneity $(P<0.05, P>50 \%)$ in the data, the sensitivity analysis was conducted to determine whether the remaining results would be markedly affected after removing outlier studies one by one. If it was not of clinical heterogeneity, a random effect model would be used. If the heterogeneity was too large to be carried out meta-analysis in the studies, the data will be analyzed one by one to be found out the reasons, and descriptive analysis will be used finally. Continuous data were expressed as standardized mean differences (SMD) and 95\% Cl. Dichotomous data were presented as ORs with $95 \% \mathrm{Cl}$. $P<0.05$ was considered statistically significant.

\section{Results}

\section{Literature search}

A total of 491 records was preliminarily identified after systematically searching the mentioned databases based on our search strategy using different search term combinations. We screened the titles and abstracts and excluded 456 irrelevant records. We scrutinized full texts of the remaining 35 papers for eligibility, and 14 papers, on a total of 1588 elderly patients with ITFs, remained for meta-analysis finally. The detailed selection process is shown in Figure 1.

\section{Characteristics of included studies}

Table 1 summarizes the characteristics of included studies. A total of 774 IF and 814 AR cases with ITFs in the elderly from 14 studies were included. Seven studies were from the Asia (China Chang,Shen,Tang,Yang, South Korea Kim,Kim,Park), ${ }^{25-31} 6$ studies were from the Europe (Turkey Kayali, Görmeli, Desteli, Özkayın, Güven , France $\left.{ }^{\text {Bonnevialle }}\right),{ }^{32-37}$ and 1 study was from Africa Gashi ${ }^{38}$ Among these eligible trials, the AR included hemiarthroplasty and total hip arthroplasty, the IF included intramedullary system (GN, PFN, PFNA, IN) and extramedullary system (CHS, DHS), which represented the commonly used implants in clinical practice. Table 2 presents the quality of the included studies. They included three RCTs (Kim 2005; Desteli 2015, Özkayın 2015); two nonrandomized prospective studies (Bonnevialle 2011; Gashi 2018), and nine retrospective analyses (Kayali 2006,Chang 2011,Shen 2012,Kim 2014, Tang 2012, Görmeli 2015, Park 2015, Güven 2016, Yang 2017).

\section{Outcome measures}

\section{Operative time}

Ten studies covered the operative time, ${ }^{25-27,29,30-35,38}$ but only the data from 8 studies, ${ }^{25,26,29,30,32-35}$ including 753 patients were eligible in the form of mean and standard deviation. High heterogeneity was present in these studies $\left(\mathrm{Chi}^{2}=129.74 ; P<0.00001 ; I^{2}=95 \%\right)$. The sensitivity analysis indicated that no significant change was found in the results after the deletion of any literature, and suggested the result is reliable. Therefore, a 
random effect model was conducted, and the result showed that there was a significant difference in the operative time between two groups (SMD= $-0.80 ; 95 \% \mathrm{Cl}=-1.47,-0.12 ; P=0.02$ ) (Fig.2). Compared with the IF group, AR group needed more operative time.

\section{Blood loss and Transfusion}

Blood loss was documented in 5 studies, ${ }^{25,27,29,31,33}$ and 2 of them including 201 patients were eligible in the form of mean and standard deviation.

29,33 The result of fixed-effect model showed that there was a significantly different in the blood loss between the two groups (SMD=-4.08; $95 \%$ $\mathrm{Cl}=-4.58,-3.59 ; P<0.00001)$ with no heterogeneity $\left(\mathrm{Chi}^{2}=0.20 ; P=0.65 ; P=0 \%\right)$ (Fig.3). IF group was superior to AR group in the blood loss.

Eight studies covered the blood transfusion, ${ }^{25-27,29,30,32,33,38}$ but only 4 studies of them provided the media volume of transfusion. ${ }^{26,29,30,32} 358$ patients were included in the remaining 4 literatures which were eligible in the form of mean and standard deviation. The heterogeneity test indicated there was a moderate heterogeneity $\left(\mathrm{Chi}^{2}=10.40, P=0.02, P^{2}=71 \%\right)$. However, sensitivity test was unnecessary because significant difference was observed in each trial, indicating the result reliable. The result of random effect model showed that the IF group has less transfusion than AR group $(\mathrm{SMD}=-0.67 ; 95 \% \mathrm{Cl}=-1.08,-0.26 ; P=0.001)$ (Fig.4).

\section{Complications-related general condition}

The general complications after surgery were reported in 8 studies (1221 patients, 189 events), ${ }^{26,27,29,30,32,33,37,38}$ which mainly included pneumonia, cardiovascular complication, urinary tract infection, neurologic complication, thromboembolic complication, pressure sores and wound infection. The heterogeneity test showed a low level among these studies $\left(C^{2}{ }^{2}=8.75, P=0.27, P=20 \%\right)$ and fixed-effect model was adopted. The incidence of postoperative complications-related general condition in AR group (91/634, 14.4\%) was slightly less than that of the IF group (98/587, $16.7 \%)$, but there was no significant difference between the two groups (OR=1.24; $95 \% \mathrm{Cl}=0.90,1.70 ; P=0.19)($ Fig.5).

\section{Complications-related operation}

Ten studies, ${ }^{25-27,29,30-32,35,37,38}$ on a total of 1212 patients, covered major method-related complications, which mainly included the dislocation, loosening, cut out, breakage, intra-operative fracture of femur, postoperative fracture of femur, nonunion, delayed union and malunion. The heterogeneity test showed a low level among these studies ( $\left.\mathrm{Chi}^{2}=14.48, P=0.11, P^{2}=38 \%\right)$ and fixed-effect model was adopted. The result indicated that there is a significant difference between $\mathrm{AR}$ and IF groups in the complications-related operation $(\mathrm{OR}=2.21 ; 95 \% \mathrm{Cl}=1.41,3.45 ; P=0.0005)$ (Fig.6), and it was clear that AR is superior to IF for the complications-related operation.

\section{Reoperation}

The rate of reoperation was reported in 7 studies. ${ }^{27,29,31,32,33,37,38}$ The total reoperation rates in the AR and IF groups were $3.83 \%$ (19/496) and $9.83 \%(45 / 458)$, respectively. A fixed effect model was followed to conduct due to a low heterogeneity $\left(\right.$ Chi $\left.{ }^{2}=8.07 ; P=0.15 ; I^{2}=38 \%\right)$, and the result showed that the AR group has a significant lower rate of reoperation than IF group $(\mathrm{OR}=2.74 ; 95 \% \mathrm{Cl}=1.57,4.76 ; P=0.0004)(\mathrm{Fig} .7)$.

\section{Hospital stay}

Nine studies covered the hospital stay, $25,27,29-31,32-34,38$ but just 6 studies including 575 patients were eligible in the form of mean and standard deviation. ${ }^{25,29,30,32-34}$ The heterogeneity test showed a high level in these studies $\left(\mathrm{Chi}^{2}=73.14, P<0.0001, P^{2}=93 \%\right)$ and random effect model was conducted. The sensitivity analysis indicated that no significant change was found in the results after the deletion of any literature, suggesting the result reliable. A random effect model was followed to conduct, and the result showed that there is no significantly different between two groups in the hospital stay $(\mathrm{SMD}=0.16 ; 95 \% \mathrm{Cl}=-0.50,0.82 ; P=0.64)$ (Fig. 8).

\section{Harris hip score}

Nine studies reported the HHS after surgery, $25-27,29,31,33,35,36,38$ but just 7 eligible studies including 704 patients in the form of mean and standard deviation were performed in the forest plot diagram. ${ }^{25,27,29,33,35,36,38}$ The heterogeneity test showed a high level among these studies $\left(\right.$ Chi $^{2}=101.52$, $\left.P<0.00001, P^{2}=94 \%\right)$ and random effect model was conducted. The sensitivity analysis indicated that no significant change was found in the results after the deletion of any literature, suggesting the result reliable. The result indicated that there is no significant difference between two groups in the $\mathrm{HHS}(\mathrm{SMD}=-0.12 ; 95 \% \mathrm{Cl}=-0.79,0.54 ; P=0.71)$ (Fig. 9).

\section{Mortality within 1-year}

A total of 10 studies reported the mortality after surgery, ${ }^{25-27,28,29,31-33,37,38}$ but just 8 of them, on a total of 1919 patients, provided the valid mortality with 1-year after surgery. ${ }^{25,27,29,31-33,37,38} \mathrm{~A}$ fixed-effect model was adopted due to no heterogeneity in these studies $\left(\mathrm{Chi}{ }^{2}=3.78, P=0.88, P^{2}=0 \%\right)$. The result showed that IF has a statistically less mortality with 1-year than $\mathrm{AR}(\mathrm{OR}=0.70 ; 95 \% \mathrm{Cl}=0.51,0.97 ; P=0.03)(\mathrm{Fig}$. 10$)$.

\section{Discussion}


It is a common understanding that ITFs need surgical treatment because of its high mortality and disability. In the past decades, DHS was the 'gold standard' for the treatment of the ITFs. ${ }^{39,40}$ With the development of biomaterials science and biomechanics, artificial hip joints and internal fixation devices have brought more choices for the treatment of ITFs. However, no consensus has been reached regarding which one leads to better clinical outcomes for the ITF. In the current systematic review and meta-analysis, we tried to resolve the contradiction raised by divergent results reported by trials comparing for IF and AR.

The combined results of meta-analysis showed no significant difference in HHS, hospital stay and complications-related general condition between the two methods. AR group had a significantly lower rate of complications-related operation and reoperation. However, compared with AR group, IF group could reduce the blood loss, transfusion requirement, operation time, and have a lower rate of mortality within 1-year.

\section{Operative time, blood loss and transfusion}

In general, relatively few operative time, intraoperative and postoperative blood loss can avoid some serious complications associated with surgery, especially for the elderly patients. Bohl et al. reported that, following adjustment for baseline characteristics, an increase in operative time by 15 minutes increased the risk of anemia requiring transfusion by $9 \%$, wound dehiscence by $13 \%$, renal insufficiency by $9 \%$, sepsis by $10 \%$, surgical site infection by $9 \%$ and urinary tract infection by $4 \% .{ }^{41}$ The other previous studies also indicated that prolonged operative time are associated with increased rates of postoperative complications, such as the surgical site infection and delayed wound healing. ${ }^{42-44}$ In the current study, our results showed that IF has a less operative time than AR. Although Park et al. reported that the operative time of IF group is similar with that of AR group, ${ }^{31}$ the other 10 included studies reported the similar result with that of meta-analysis. ${ }^{25-27,29,30,32-35,38}$ Therefore, we think that the overall data of IF group is superior to AR group in the operative time.

Normally, the shorter the operation time, the less blood loss associated with the operation. Additionally, the effect of different surgical methods on blood loss is also very important. In the current study, the initial meta-analysis is reliable, but obviously, the data only including 201 cases may be not enough. Therefore, the described analysis was conducted, and it was confirmed that the included 5 studies, on a total 552 cases, all reported the same result, which is that the blood loss in the IF group is statistically less than that of AR group. Correspondingly, the current meta-analysis indicated that internal fixation was superior to arthroplasty in terms of blood transfusion volume. In the last ten years, the devices of intramedullary fixation, such as PFN, PFNA, GN and IN, have been widely used. The postoperative hidden blood loss caused by the intramedullary fixation has attracted more and more attention. A few literatures showed that the postoperative hidden blood loss is more than intra-operative blood loss. ${ }^{45-47}$ Unfortunately, this presented meta-analysis didn't analyze the hidden blood loss. Therefore, only analyzing intraoperative blood loss may be unfair for the AR group. We suggest that the hidden blood loss should be included in the comparison of IF and AR for the blood loss.

\section{Postoperative complications and Reoperation}

The analysis of postoperative complications is helpful to prevent their occurrence and improve the success rate of surgery. For elderly patients with hip fractures, the general complications include hematoma, infection, bedsore, pneumonia, urinary tract infection and thromboembolism. In this meta-analysis, eight articles reported postoperative general complications, ${ }^{26,27,29,30,32,33,37,38}$ and the result showed that there was no significant difference in the postoperative general complications between IF and AR group. This is consistent with previous reports. ${ }^{48,49}$ In contrast to the incidence of general complications after surgery, our results showed that the complications-related operation and rate of reoperation of the AR group are better than that of the IF group. A total of ten articles compared the complications-related operation of the two groups. ${ }^{25-27,29-32,35,37,38}$ In the IF group, the lowest incidence of complications-related operation was approximately $4.8 \%(1 / 21)$, and the highest incidence of complications-related operation was approximately $24.1 \%(7 / 29)$. In the AR group, the lowest incidence of complications-related operation was $0 \%$, and the highest incidence of complications-related operation was approximately $22.7 \%$ (5/22). In the IF group, 5 articles reported that the incidence of complicationsrelated operation was over $10 \%$. However, in the AR group, only 1 article reported a complication rate of more than $10 \%$, and even two reported were zero. Obviously, the incidence of complications-related operation in the AR group was significantly lower than that in the IF group. Certainly, complications do not necessarily mean reoperation. However, it is clear that failure of internal fixation is one of the main causes of reoperation. Therefore, we also analyzed the reoperation rate of the two groups through this meta-analysis. The results showed that the reoperation rate of the AR group is also significantly lower than that of the IF group. It suggested that more attention should be paid to the properties of biomaterials and biomechanics for the future development of internal fixation devices.

\section{Hospital stay, Harris hip score}

Early discharge and a good postoperative joint function are essential for the elderly with fractures. In general, relatively larger operation may result in longer hospital stay for the senile patients. In the current study, the results showed that there is no essentially difference in the hospital stay between the IF and AR groups. It has been reported in the literatures that patients with AR can bear weight earlier than those with IF, $3,6,8,11$ but there was no statistical difference in the final HHS after a follow-up period of more than half a year between the two groups. However, early weight bearing helps reduce bedridden-related complications, such as the deep venous thrombosis, pneumonia and urinary tract infection. ${ }^{50-53}$ Therefore, AR appears to be superior to IF in terms of early weight bearing. 
Mortality rate after surgery is an important indicator to evaluate the surgical effectiveness. The current meta-analysis showed that the mortality rate within 1-year of the IF group was lower than that of the AR group. Another meta-analysis also showed that the mortality rate within 1-year in the intramedullary fixation group was reduced significantly compared with the AR group. ${ }^{54}$ In addition, it has been reported that the IF group has a lower 3-year mortality rate than the AR group. ${ }^{2,9}$

\section{Limitations}

Some limitations in the present systematic review and meta-analysis should be noted. First, we limited the published language in English and this might lead to a certain degree of bias. Second, the number of inclusive studies and patients are relatively few which only 14 publications met the eligibility criteria. Third, the quality of the trials was generally low, except for 3 RCTs and 2 prospective nonrandomized trials, the others were retrospective comparative study. Fourth, we did not analysis the effect of treatments on ITF according to different ages and fracture classifications because of the limitation of the studies included, which may affect the results. Fifth, our study may also be influenced by the lack of data for longterm and different follow-up duration of included studies. Furthermore, meta-analysis is a retrospective research tool that is subject to methodological deficiencies.

In conclusion, the present study suggests that AR provides less complications-related operation and reoperation rate when compared with IF for the elderly with ITFs, but has no obvious statistical difference in terms of hospital stay, postoperative functional assessment and complications-related general condition. However, IF is superior to arthroplasty in terms of operative time, blood loss, transfusion and mortality within 1-year. Obviously, AR does not offer a clear advantage over internal fixation for the elderly with ITFs. Therefore, in view of the current dominance of internal fixation, we suggest that larger and well-designed, randomized controlled studies with longer-term follow-ups are needed to verify whether arthroplasty should be the optimal treatment for the elderly patients with ITFs in the future.

\section{Declarations}

\section{Acknowledgments}

This work was supported by the plan of young and middle-aged medical high-end

reserve talent of Chongqing (No. 2017HBRC012).

\section{Disclosure}

The authors report no conflicts of interest in this work.

Author contributions $₫$ Kexiao Yu, Zhenyu Dai: planed, performed, analyzed the data and wrote the manuscript. Zhenyu Dai, Weizhong Lu: conceived the idea and designed the study. Qiuke Xiao, Ruijie Wan, Lujue Dong: primarily responsible for the data collection and analysis. All authors discussed the results and commented on the manuscript.

Availability of Data and Materials $\square$ The datasets used and/or analysed during the current study are available from the corresponding author on reasonable request.

\section{References}

1. Gullberg B, Johnell O, Kanis JA. World-wide projections for hip fracture. Osteoporosis Int. 1997;7(5):407-413.

2. Lee SH, Chen IJ, Li YH, Fan Chiang CY, Chang CH, Hsieh PH. Incidence of second hip fractures and associated mortality in Taiwan: A nationwide population based study of 95,484 patients during 2006-2010. Acta Orthop Traumatol Turc. 2016;50(4):437-442.

3. Yan SG, Zhao X, Li H, et al. Comparison of percutaneous compression plating and short reconstruction nail for treatment of intertrochanteric fracture. Orthop Surg. 2011;3(1):14-21.

4. Horwitz DS, Tawari A, Suk M. Nail Length in the Management of Intertrochanteric Fracture of the Femur. J Am Acad Orthop Surg.2016;24(6):e5058.

5. Roth T, Kammerlander C, Gosch M, Luger TJ, Blauth M. Outcome in geriatric fracture patients and how it can be improved. Osteoporos Int. 2010;21(Suppl.4):S615-S619.

6. Marsh JL, Slongo TF, Agel J, et al. Fracture and dislocation classification compendium-2007: Orthopaedic Trauma Association classification, database and outcomes committee. J Orthop Trauma. 2007;21(10 Suppl):S1-S133.

7. Little NJ, Verma V, Fernando C, Elliott DS, Khaleel A. A prospective trial comparing the Holland nail with the dynamic hip screw in the treatment of intertrochanteric fractures of the hip. J Bone Joint Surg Br. 2008;90(8):1073-1078.

8. Holt G, Smith R, Duncan K, Hutchison JD, Gregori A. Outcome after surgery for the treatment of hip fracture in the extremely elderly. J Bone Joint Surg Am. 2008;90(9): 1899-1905. 
9. Zhao X, Yan SG, Li H, Wu HB. Short reconstruction nail for intertrochanteric fracture: does it really fit Asian feature? Arch Orthop Trauma Surg. 2012;132(1):81-86.

10. Kumar R, Singh RN, Singh BN. Comparative prospective study of proximal femoral nail and dynamic hip screw in treatment of intertrochanteric fracture femur. J Clin Orthop Trauma. 2012;3(1):28-36.

11. Koval KJ, Aharonoff GB, Su ET, Zuckerman JD. Effect of acute inpatient rehabilitation on outcome after fracture of the femoral neck or intertrochanteric fracture. J Bone Joint Surg Am. 1998;80(3):357-364.

12. Desjardins AL, Roy A, Paiement G, et al. Unstable intertrochanteric fracture of the femur. A prospective randomised study comparing anatomical reduction and medial displacement osteotomy. J Bone Joint Surg Br. 1993;75(3):445-447.

13. Desteli E, Imren Y, Erdoğan M, Aydagün Ö. Quality of life following treatment of trochanteric fractures with proximal femoral nail versus cementless bipolar hemiarthroplasty in elderly. Clin Invest Med. 2015;38(2):E63-72.

14. Arslan A, Utkan A, Koca TT. Results of a compression pin along with trochanteric external fixation in management of high risk elderly intertrochanteric fractures. Indian J Orthop. 2016;50(6):636-640.

15. Yu X, Wang H, Duan X, Liu M, Xiang Z. Intramedullary versus extramedullary internal fixation for unstable intertrochanteric fracture, a metaanalysis. Acta Orthop Traumatol Turc.2018;52(4):299-307.

16. Göçer H, Coşkun S, Karaismailoğlu N. Comparison of treatment of unstable intertrochanteric fracture with different arthroplasty methods. Niger Med J.2016;57(2):81-85.

17. Guerra MT, Pasqualin S, Souza MP, Lenz R. Functional recovery of elderly patients with surgically-treated intertrochanteric fractures: preliminary results of a randomised trial comparing the dynamic hip screw and proximal femoral nail techniques. 2014;45 (Suppl 5):S26-31.

18. Barquet A, Mayora G, Guimaraes JM, Suárez R, Giannoudis PV. Avascular necrosis of the femoral head following trochanteric fractures in adults: a systematic review. Injury. 2014;45 (12):1848-1858.

19. Hou G, Zhou F, Tian Y, et al. Predicting the need for blood transfusions in elderly patients with pertrochanteric femoral fractures. 2014;45(12):1932-1937.

20. Steinberg EL, Amar E, Sagy Y, Rath E, Kadar A, Sternheim A. The impact of serum albumin and serum protein levels on POSSUM score of patients with proximal femur fractures. 2014;45 (12):1928-1931.

21. Baratz MD, Hu YY, Zurakowski D, Appleton P, Rodriguez EK. The primary determinants of radiation use during fixation of proximal femur fractures. 2014;45 (10):1614-1649.

22. Faroug R, Amanat S, Ockendon M, Shah SV, Gregory JJ. The outcome of patients sustaining a proximal femur fracture who suffer from alcohol dependency. 2014;45 (7):1076-1079.

23. Dai Z, Li Y, Jiang D. Meta-analysis comparing arthroplasty with internal fixation for displaced femoral neck fracture in the elderly. J Surg Res. 2011;165(1):68-74.

24. Murphy SW. Longitudinal studies and determination of risk. Methods Mol Biol. 2009;473:19-37.

25. Chang Q, Liu S, Guan C, Yu F, Wu S, Jiang C. Bipolarhip J Arthroplasty. 2011;26(8):1455-1459.

26. Shen J, Wang DL, Chen GX, et al. Bipolarhemiarthroplasty compared with internal fixation for unstable intertrochanteric fractures in elderly patients. J Orthop Sci. 2012;17(6):722-729.

27. Tang P, Hu F, Shen J, Zhang L, Zhang L. Proximal femoral nail antirotation versus hemiarthroplasty: a study for the treatment of intertrochanteric fractures. 2012;43(6): 876-881.

28. Yang ZB, Wu PH, Wong PK, et al. Better Prognosis of Senile Patients with Intertrochanteric Femoral Fracture by treatment with Open Reduction Internal Fixation by Hip Arthroplasty. J Invest Surg. 2017;19:1-7.

29. Kim SY, Kim YG, Hwang JK.Cementlesscalcar-replacement hemiarthroplasty compared with intramedullary fixation of unstable intertrochanteric fractures. A prospective, randomized study. J Bone Joint Surg Am. 200;87(10):21862192.

30. Kim YS, Hur JS, Hwang KT, Choi IY, Kim YH. The Comparisonof Compression Hip Screw and Bipolar Hemiarthroplasty for the Treatment of AO Type A2 Intertrochanteric Fractures. Hip Pelvis. 2014;26(2):99-106.

31. Park BJ, Cho HM, Min WB. A Comparisonof Internal Fixation and Bipolar Hemiarthroplasty for the Treatment of ReverseOblique Intertrochanteric Femoral Fractures in Elderly Patients. Hip Pelvis. 2015;27(3):152-163.

32. Kayali C, Agus H, Ozluk S, Sanli C. Treatmentfor unstable intertrochanteric fractures in elderly patients: internal fixation versuscone hemiarthroplasty. J Orthop Surg (Hong Kong). 2006;14(3):240-244. 
33. Görmeli G, Korkmaz MF, Görmeli CA, Adanaş C, Karataş T, Şimşek SA. Comparison of Femur

intertrochanteric fracture fixation with hemiarthroplasty and proximalfemoral nail systems. Ulus Travma Acil Cerrahi Derg. 2015;21(6):503-508.

34. Desteli EE, İmren Y, Erdoğan M, Aydagün Ö. Qualityof Life Following Treatment of Trochanteric Fractures with Proximal Femoral Nail versus Cementless Bipolar Hemiarthroplasty in Elderly. Clin Invest Med. 2015;38(2):E63-72.

35. Özkayın N, Okçu G, Aktuğlu K. Intertrochantericfemur fractures in the elderly treated with either proximal femur nailing or hemiarthroplasty: A prospective randomised clinical study. 2015;46 Suppl 2:S3-8.

36. Güven M, Kocadal O, Akman B, Poyanlı OS, Kemah B, Atay EF. Proximalfemoral nail Shows better concordance of gait analysis between operated and uninjured limbs compared to hemiarthroplasty in intertrochanteric femoral fractures. Injury. 2016;47(6):1325-1331.

37. Bonnevialle $P$, Saragaglia D, Ehlinger $M$, et al. Trochantericlocking nail versus arthroplasty in unstable intertrochanteric fracture in patients aged over 75 years. Orthop Traumatol Surg Res. 2011;97(6 Suppl):S95-100.

38. Gashi YN, Elhadi AS, Elbushra

IM.Outcomeof Primary Cemented Bipolar Hemiarthroplastycompared with Dynamic Hip Screw in Elderly Patients with Unstable Intertrochanteric Fracture. Malays Orthop J. 2018;12(1):36-41.

39. Asif N, Ahmad S, Qureshi OA, Jilani LZ, Hamesh T, Jameel T. Unstablelntertrochanteric Fracture Fixation -

Is Proximal Femoral Locked Compression Plate Better Than Dynamic Hip Screw. J Clin Diagn Res. 2016;10(1):RC09-13.

40. Jonnes C, Sm S, Najimudeen S. Type II Intertrochanteric Fractures: Proximal Femoral Nailing (PFN) Versus Dynamic Hip Screw (DHS). Arch Bone Jt Surg. 2016;4(1):23-28.

41. Bohl DD, Ondeck NT, Darrith B, Hannon CP, Fillingham YA, Della Valle CJ. Impact of Operative Time on Adverse Events Following Primary Total Joint Arthroplasty. J Arthroplasty. 2018;33(7):2256-2262.

42. Wills BW, Sheppard ED, Smith WR, et al. Impact of operative time on early joint infection and deep vein thrombosis in primary total hip arthroplasty. Orthop Traumatol Surg Res. 2018;104(4):445-448.

43. Colman M, Wright A, Gruen G, Siska P, Pape HC, Tarkin I. Prolonged operative time increases infection rate in tibial plateau fractures. 2013;44(2):249-52.

44. Aigner R, Salomia C, Lechler P, Pahl R, Frink M. Relationship of Prolonged Operative Time and Comorbidities With Complications After Geriatric Ankle Fractures. Foot Ankle Int. 2017;38(1):41-48.

45. Yang X, Wu Q, Wang X. Investigation of perioperative hidden blood loss of unstable intertrochanteric fracture in the elderly treated with different intramedullary fixations. 2017;48(8):1848-1852.

46. Li B, Li J, Wang S, Liu L. Clinical analysis of peri-operative hidden blood loss of elderly patients with intertrochanteric fractures treated by unreamed proximal femoral nail anti-rotation. Sci Rep. 2018;8(1):3225-3230.

47. Tian S, Shen Z, Liu Y, Zhang Y, Peng A. The effect of tranexamic acid on hidden bleeding in older intertrochanteric fracture patients treated with PFNA. 2018;49(3):680-684.

48. Parker MJ, Handoll HH. Replacement arthroplasty versus internal fixation for extracapsular hip fractures in adults. Cochrane Database Syst Rev. 2006;(2):CD000086.

49. Yoo JI, Ha YC, Lim JY, Kang H, Yoon BH, Kim H. Early Rehabilitation in Elderly after Arthroplasty versus Internal Fixation for Unstable Intertrochanteric Fractures of Femur: Systematic Review and Meta-Analysis. J Korean Med Sci. 2017;32(5):858-867.

50. Hickey BA, Cleves A, Alikhan R, Pugh N, Nokes L, Perera A. The effect of active toe movement (AToM) on calf pump function and deep vein thrombosis in patients with acute foot and ankle trauma treated with cast - A prospective randomized study. Foot Ankle Surg.2017;23(3):183188.

51. Jiang Y, Yao JF, Xiong YM, Ma JB, Kang H, Xu P. No Superiority of High-Flexion vs Standard Total Knee Arthroplasty: An Update Meta-Analysis of Randomized Controlled Trials. J Arthroplasty.2015;30(6):980-986.

52. Riou B, Rothmann C, Lecoules $\mathrm{N}$, et al. Incidence and risk factors for venous thromboembolism in patients with nonsurgical isolated lower limb injuries. Am J Emerg Med.2007;25(5):502-508.

53. Ragucci MV, Leali A, Moroz A, Fetto J. Comprehensive deep venous thrombosis prevention strategy after total-knee arthroplasty. Am J Phys Med Rehabil.2003;82(3):164-168.

54. Nie B, Wu D, Yang Z, Liu Q. Comparison of intramedullary fixation and arthroplasty for the treatment of intertrochanteric hip fractures in the elderly: A meta-analysis. Medicine (Baltimore).2017;96(27):e7446-7453.

\section{Tables}


Table. 1. Characteristics of the included studies

\begin{tabular}{|c|c|c|c|c|c|c|c|c|c|}
\hline \multirow[t]{2}{*}{ Studies } & \multirow[t]{2}{*}{ Year } & \multicolumn{2}{|c|}{ №. of patients } & \multicolumn{2}{|c|}{ Mean age(y) } & \multicolumn{2}{|c|}{ Interventions } & \multirow{2}{*}{$\begin{array}{l}\text { Follow-up } \\
\text { (AR/F, months) }\end{array}$} & \multirow[t]{2}{*}{ Outcomes } \\
\hline & & $\mathrm{AR}$ & IF & $\mathrm{AR}$ & IF & $A R$ & IF & & \\
\hline Kim & 2005 & 29 & 29 & $82.0+3.4$ & $81.0 \div 3.2$ & $\mathrm{HA}$ & $\mathrm{PFN}$ & $35(24-58) / 34(24-57)$ & $1-9$ \\
\hline Kayali & 2006 & 42 & 45 & $73(60-103)$ & $75(62-82)$ & HA & DHS & $24(12-40) / 29(12-52)$ & $1,3-8$ \\
\hline Bonnevialle & 2011 & 134 & 113 & 85.9 & 85.5 & HNTHA & GN & 6 & $4-6,8$ \\
\hline Chang & 2011 & 70 & 42 & $81.81 \pm 4.8$ & $83.46 \div 5.1$ & НА & DHS & $>12$ & $1-4,7-9$ \\
\hline Shen & 2012 & 60 & 64 & $78.2(70-101)$ & $76.8(70-98)$ & HA & DHSIN & 24 & $14,6,8,9$ \\
\hline Kim & 2014 & 46 & 43 & $79.7 \pm 6.5$ & $75.5 \pm 6.4$ & НА & CHS & $25.2+18.028 .8+19.2$ & $1,3,4,6,7$ \\
\hline Tang & 2012 & 156 & 134 & 81.145 .8 & $80.6 \pm 6.9$ & HA & PFNA & $44.2 \pm 6.9 / 35.9 \pm 8.6$ & $1-9$ \\
\hline Görmeli & 2015 & 75 & 68 & $76.2+7.9$ & $77.4+8.4$ & HA & PFN & $29.6 \pm 10.3 / 32.3+8.9$ & $1-3,5-9$ \\
\hline Park & 2015 & 22 & 31 & $76.9(70-84)$ & $78.1(73-86)$ & $\mathrm{HA}$ & PFNPFNA & 24 & $1,2,4,5,7-11$ \\
\hline Desteli & 2015 & 44 & 42 & $65.0 \pm 1.52$ & $67.0 \pm 1.21$ & HA & PFNA & 24 & 1,7 \\
\hline Özkayn & 2015 & 33 & 21 & $83.94 \div 4.92$ & $79.57 \pm 4.83$ & HANTHA & $\mathrm{PFN}$ & $31.33 \pm 10.65 / 32.33 \pm 10.97$ & $1,4,6,9$ \\
\hline Güven & 2016 & 16 & 21 & $79 \pm 5.7$ & $78 \pm 6.8$ & HA & DHS & $30 \pm 7.3 / 36 \pm 8.4$ & 9 \\
\hline Yang & 2017 & 27 & 83 & $79.98+6.0$ & $78.87 \pm 7.72$ & HАТTA & DHS & $51.6 \pm 26.5 / 45.4 \pm 30.4$ & 8 \\
\hline Cashi & 2018 & 60 & 38 & $76.15 \pm 67.2$ & $79.3 \pm 11.0$ & HA & DHS & $13.66 \pm 5.9 / 11.8 \pm 2.7$ & $1,3,49$ \\
\hline
\end{tabular}

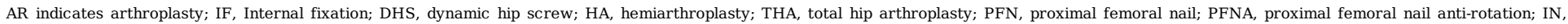
interTan; CHS, compression hip screw; GN, gamma nail.

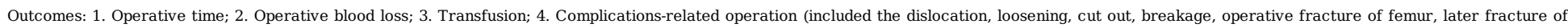

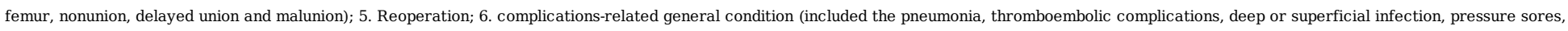
hematoma); 7. Length of hospital stay; 8. Mortality; 9. Harris hip score

Table. 2. Quality of included studies

\begin{tabular}{|c|c|c|c|c|c|c|c|}
\hline Studies & $\begin{array}{l}\text { Random sequence } \\
\text { generation }\end{array}$ & $\begin{array}{l}\text { Allocation } \\
\text { concealment }\end{array}$ & Blinding of participants and personnel & $\begin{array}{l}\text { Blinding of } \\
\text { outcome assessment }\end{array}$ & $\begin{array}{l}\text { Incomplete } \\
\text { outcome data }\end{array}$ & Selective reporting & Other Bias \\
\hline Kim2005 & Low risk & Low risk & Unclear & Unclear & Low risk & Low risk & Low risk \\
\hline Kayali2006 & High risk & Low risk & Unclear & Unclear & Low risk & Low risk & Low risk \\
\hline Bonnevialle2011 & High risk & Low risk & Unclear & High risk & Low risk & Low risk & Low risk \\
\hline Chang2011 & High risk & Low risk & Unclear & Unclear & Low risk & Low risk & Low risk \\
\hline Shen2012 & High risk & Low risk & Low risk & High risk & Low risk & Low risk & Low risk \\
\hline Kim2014 & High risk & Low risk & Unclear & Unclear & Low risk & Low risk & Low risk \\
\hline Tang2012 & High risk & Low risk & Unclear & Unclear & Low risk & Low risk & Low risk \\
\hline Görmeli2015 & High risk & Low risk & Unclear & High risk & Low risk & Low risk & Low risk \\
\hline Park2015 & High risk & Low risk & Low risk & High risk & Low risk & Low risk & Low risk \\
\hline Desteli2015 & Low risk & Unclear & Low risk & Unclear & Low risk & Low risk & Low risk \\
\hline Özkayın2015 & Low risk & Low risk & Low risk & Unclear & Low risk & Low risk & Low risk \\
\hline Güven2016 & High risk & Low risk & Unclear & Unclear & Low risk & Low risk & Low risk \\
\hline Yang2017 & High risk & Low risk & Unclear & High risk & Low risk & Low risk & Low risk \\
\hline Gashi2018 & Low risk & Low risk & Low risk & Unclear & Low risk & Low risk & Low risk \\
\hline
\end{tabular}

Figures 


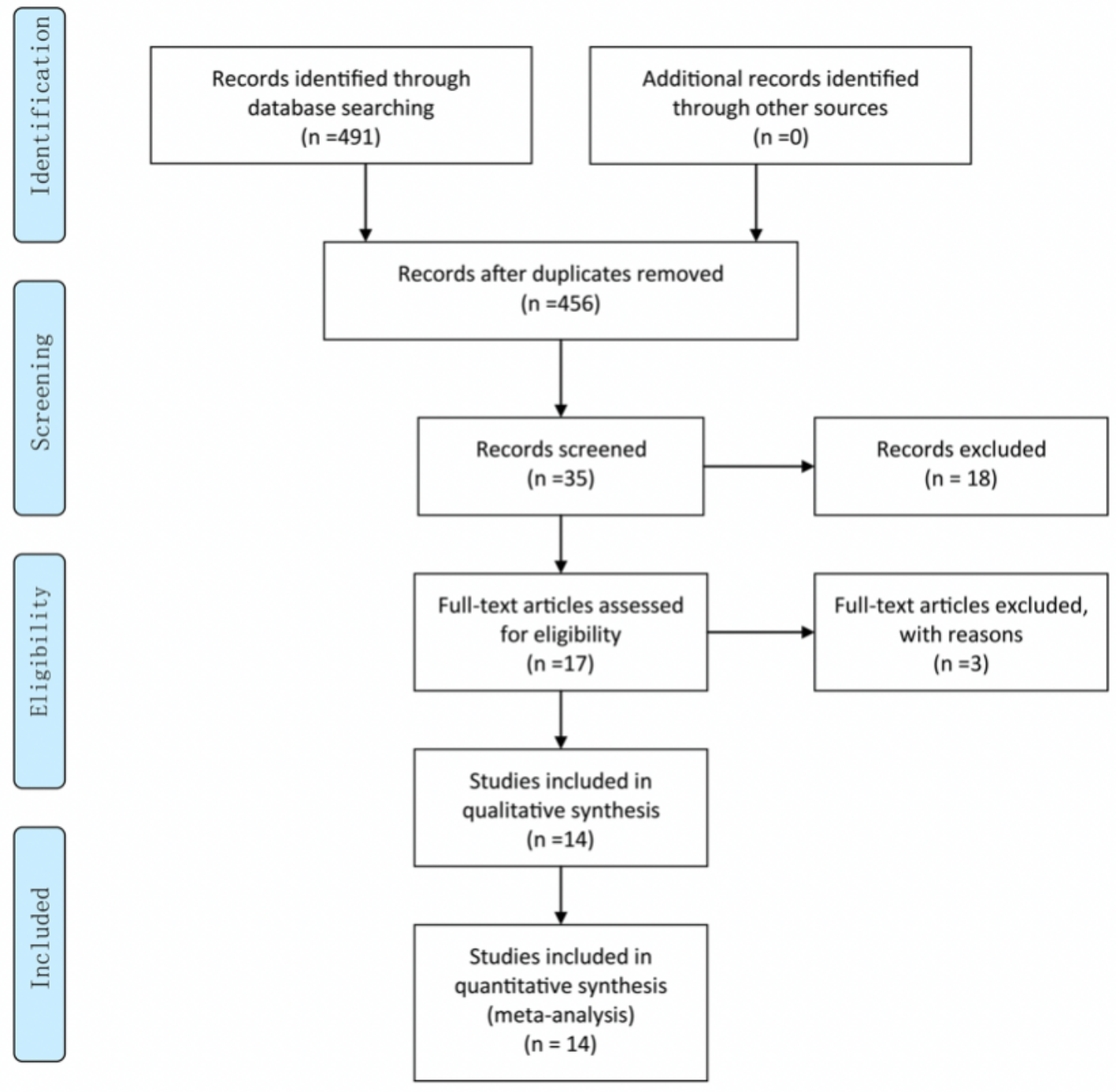

Figure 1

PRISMA flow diagram of study selection process.

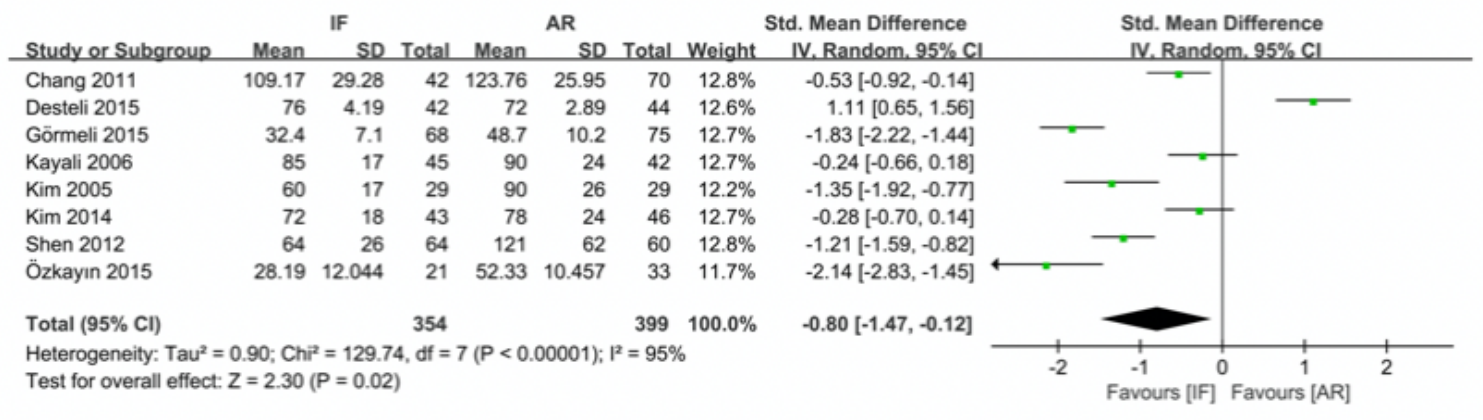

Figure 2

The comparison of operative time between IF and AR groups. 


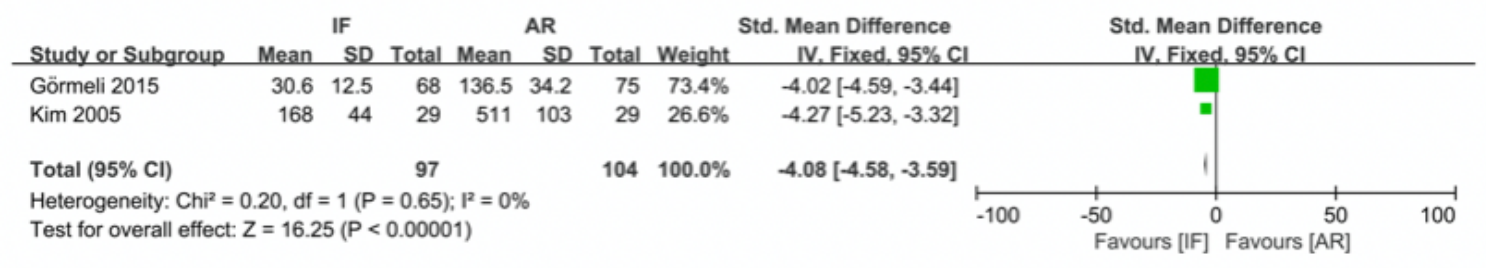

Figure 3

The comparison of blood loss between IF and AR groups.

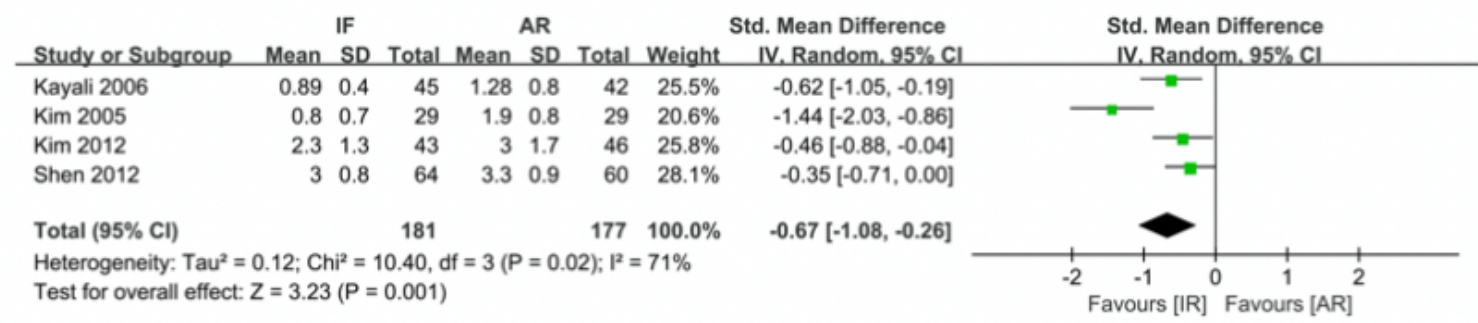

\section{Figure 4}

The comparison of transfusion between IF and AR groups.

\begin{tabular}{|c|c|c|c|c|c|c|c|c|c|c|}
\hline Study or Subgroup & $\begin{array}{r}\text { IF } \\
\text { Events }\end{array}$ & Total & $\begin{array}{r}\text { AR } \\
\text { Events }\end{array}$ & Total & Weight & $\begin{array}{c}\text { Odds Ratio } \\
\text { M-H. Fixed. } 95 \% \mathrm{Cl}\end{array}$ & & $\begin{array}{r}\text { Odds F } \\
M-H \text {. Fixec }\end{array}$ & $\begin{array}{l}\text { Ratio } \\
\text { d. } 95 \% \mathrm{Cl}\end{array}$ & \\
\hline Bonnevialle 2011 & 19 & 113 & 15 & 134 & $16.7 \%$ & $1.60[0.77,3.32]$ & & & $=$ & \\
\hline Gashi 2018 & 12 & 38 & 10 & 60 & $7.8 \%$ & $2.31[0.88,6.05]$ & & & & \\
\hline Görmeli 2015 & 19 & 68 & 24 & 75 & $24.0 \%$ & $0.82[0.40,1.69]$ & & & & \\
\hline Kayali 2006 & 11 & 64 & 5 & 60 & $6.2 \%$ & $2.28[0.74,7.01]$ & & & & \\
\hline Kim 2005 & 8 & 29 & 12 & 29 & $12.7 \%$ & $0.54[0.18,1.62]$ & & & & \\
\hline Kim 2014 & 11 & 64 & 5 & 60 & $6.2 \%$ & $2.28[0.74,7.01]$ & & & & \\
\hline Shen 2012 & 6 & 64 & 5 & 60 & $6.8 \%$ & $1.14[0.33,3.94]$ & & & & \\
\hline Tang 2012 & 12 & 147 & 15 & 156 & $19.5 \%$ & $0.84[0.38,1.85]$ & & & & \\
\hline Total $(95 \% \mathrm{Cl})$ & & 587 & & 634 & $100.0 \%$ & $1.24[0.90,1.70]$ & & & & \\
\hline Total events & $\begin{array}{c}98 \\
76=7\end{array}$ & & $\begin{array}{c}91 \\
271 \cdot 1^{2}=?\end{array}$ & & & & & & & \\
\hline $\begin{array}{l}\text { Heterogeneity: } \mathrm{Chi}^{2}= \\
\text { Test for overall effect: }\end{array}$ & $\begin{array}{l}75, \mathrm{df}=7 \\
=1.32(P\end{array}$ & $\begin{array}{l}7(P=0 \\
P=0.19\end{array}$ & .27); $1^{2}=2$ & $20 \%$ & & & 0.2 & $\begin{array}{cc}0.5 & 1 \\
\text { Favours [IR] }\end{array}$ & $1 \frac{2}{\text { Favours [AR] }}$ & 5 \\
\hline
\end{tabular}

Figure 5

The comparison of postoperative complications-related general condition between IF and AR groups.

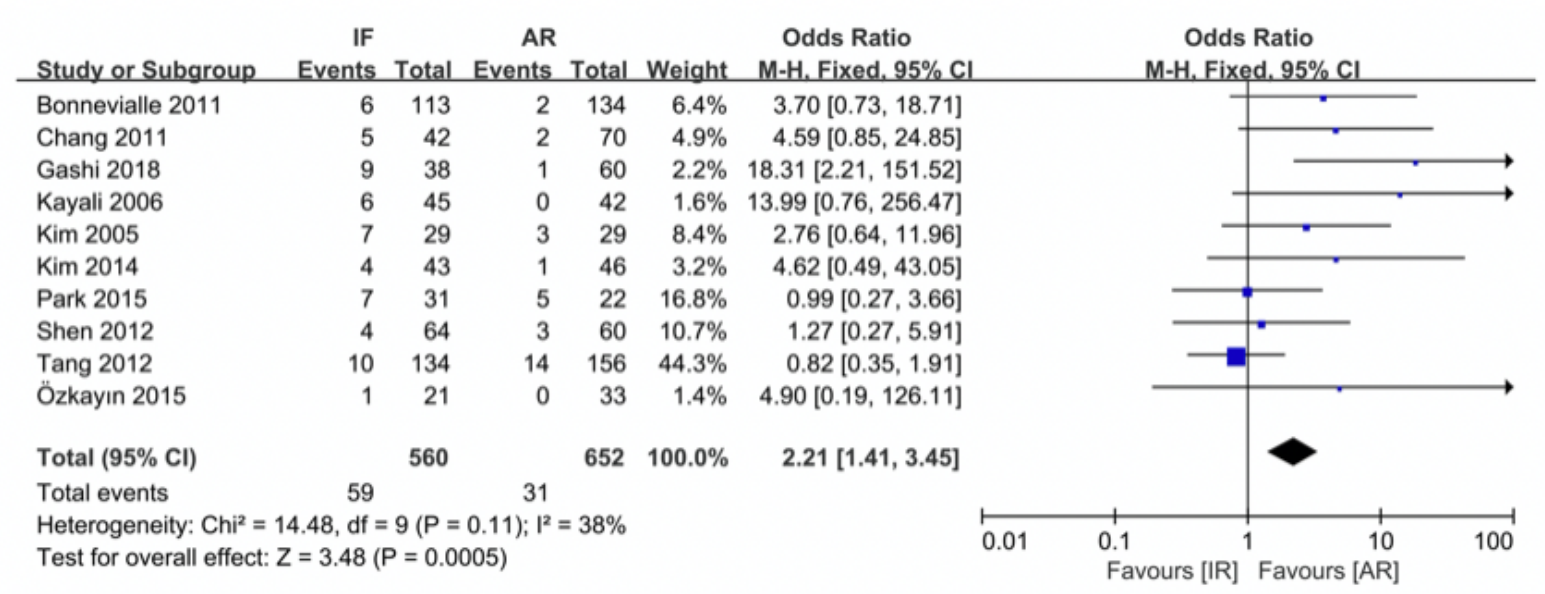




\section{Figure 6}

The comparison of postoperative complications-related operation between IF and AR groups.

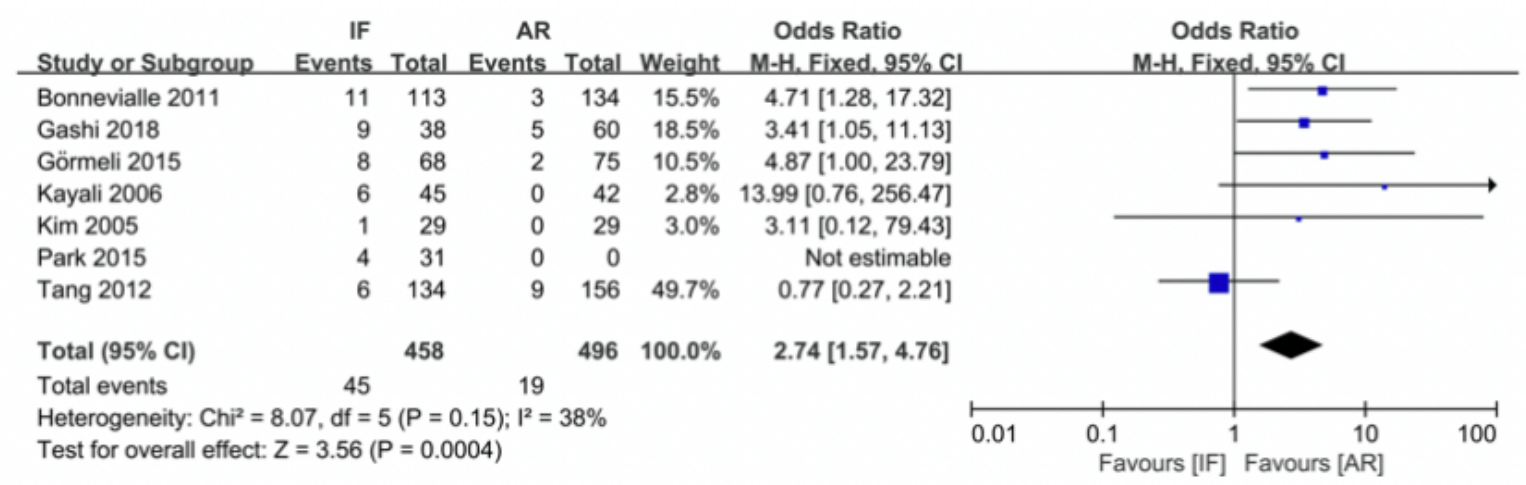

Figure 7

The comparison of reoperation between IF and AR groups.

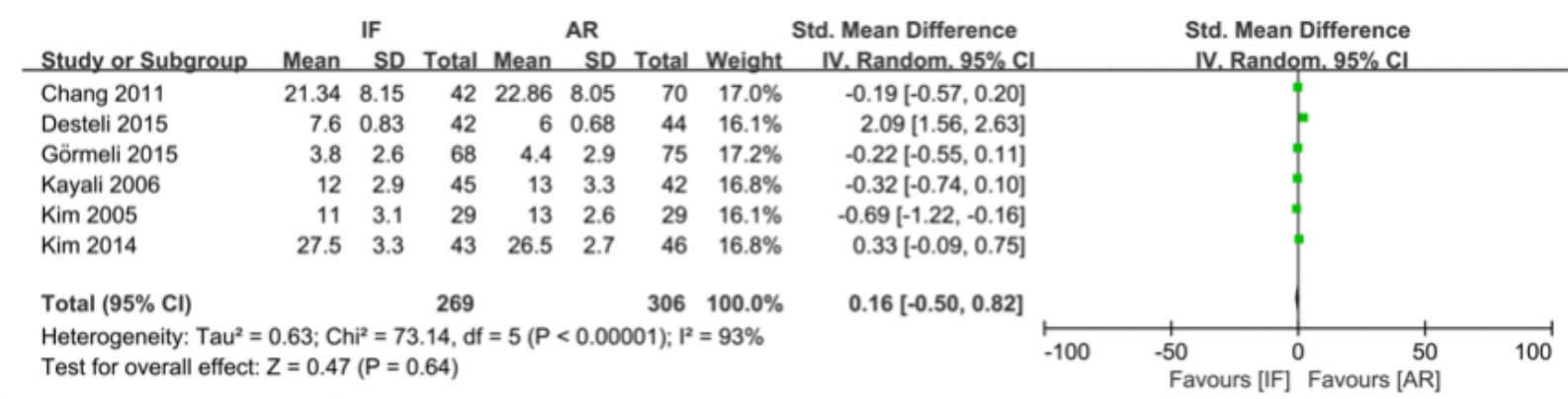

\section{Figure 8}

The comparison of hospital stay between IF and AR groups.

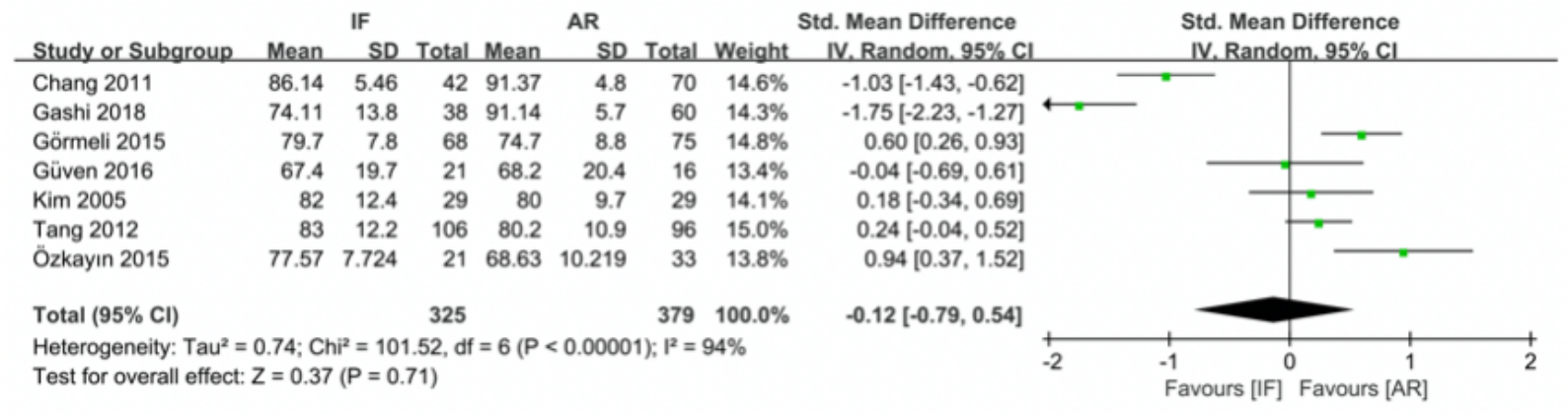

\section{Figure 9}

The comparison of Harris hip score between IF and AR groups. 


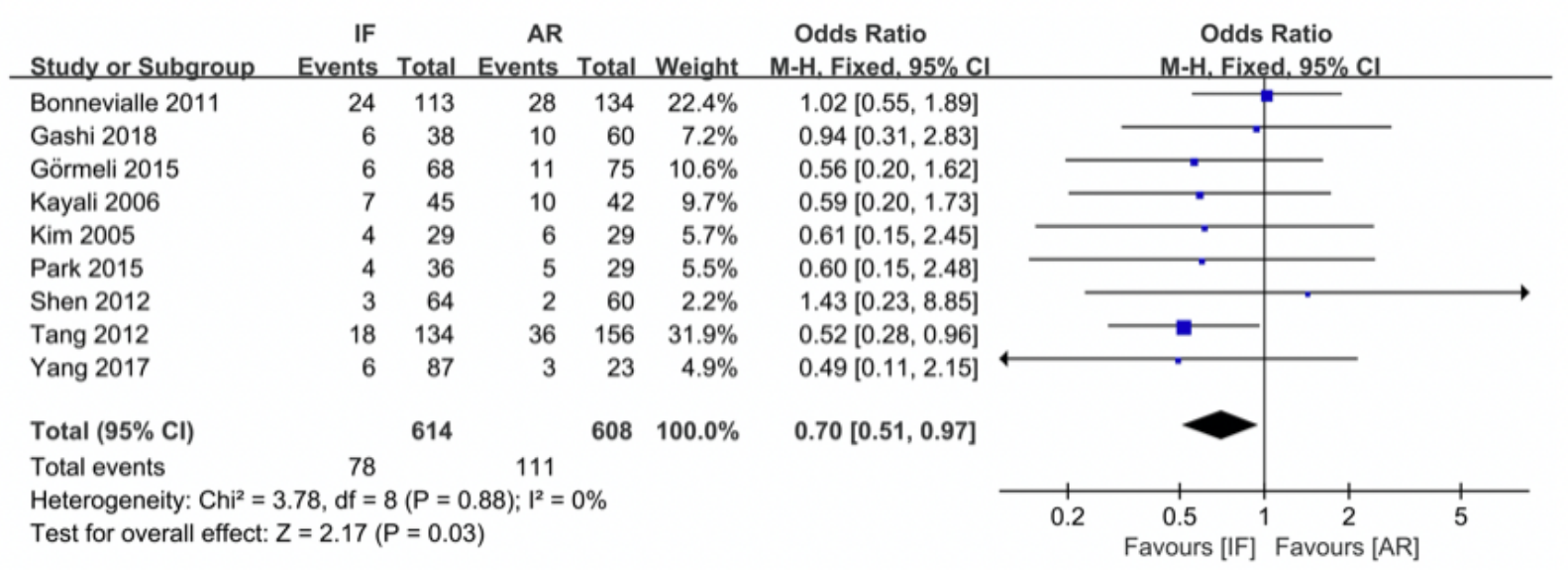

\section{Figure 10}

The comparison of mortality within 1-year between IF and AR groups. 